\title{
A construção da imagem internacional do Brasil por meio da cultura. Do Gabinete de Curiosidades à cerimônia de abertura dos Jogos Olímpicos no Brasil.
}

MARIA IGNEZ MANTOVANI FRANCO

Maria Ignez Mantovani Franco é doutora em Museologia pela Universidade Lusófona de Humanidades e Tecnologias, de Lisboa, Portugal (2009), graduou-se em Comunicação Social pela Fundação Armando Álvares Penteado (1976). É diretora da EXPOMUS - Exposições, Museus, Projetos Culturais, por ela criada em 1981, empresa onde desenvolve projetos de exposições nacionais e internacionais de arte e cultura brasileira, além de projetos museológicos, socioeducacionais e ambientais, em colaboração com instituições e museus no Brasil e no exterior. É presidente do ICOM Brasil desde 2012 e sua representante junto ao Conselho Consultivo do Patrimônio Museológico do IBRAM - Instituto Brasileiro de Museus. 


\section{RESUMO}

O artigo aborda o deslocamento humano pelo planeta, em diferentes épocas, como uma longa permanência em busca de conhecimento, domínio e ocupação de territórios. Evidencia que a partir das primeiras trocas humanas até a atualidade, a cultura expressa a intrínseca relação do homem com o seu ambiente, por meio dos artefatos que compõem seu universo simbólico.

Como instrumento preponderante para relatar e dar conhecimento às matrizes europeias sobre as descobertas nos trópicos, os relatos dos viajantes europeus foram sempre acompanhados de desenhos, ilustrações, mapas, gravuras e espécies naturais, que vieram a compor as Câmaras de Maravilhas, capazes de encantar e seduzir os europeus no século XVI. Assim, dos Gabinetes de Curiosidades à cerimônia de abertura dos Jogos Olímpicos no Brasil, a cultura brasileira manifesta seu enorme potencial de estreitar caminhos para uma diplomacia cultural de excelência, que poderá representar grande estratégia de inclusão do país no sistema econômico global. O artigo analisa a participação do Brasil em alguns eventos culturais internacionais de expressão, e reflete sobre a cultura como elemento de soft power no contexto das relações internacionais.

PALAVRAS-CAVE

Cultura, globalização, soft power, diplomacia cultural, jogos olímpicos.

\section{ABSTRACT}

The article discusses human displacement on the planet, through different ages, looking permanently for knowledge, domain and occupation of territories. It highlights that from the first human exchanges to the present, culture expresses the intrinsic relationship of humankind with its environment, through the artifacts that are part of its symbolic universe.

Used as a major instrument to inform, to let European headquarters know about the discoveries in the tropics, the reports of European travelers were always accompanied by drawings, illustrations, maps, engravings and natural species that formed the Wonder Rooms, in order to delight and seduce Europeans in the 16th century. Thus, from the Cabinets of Curiosities to the opening ceremony of the Olympic Games in Brazil, Brazilian culture expresses its enormous potential to narrow paths for a cultural diplomacy of excellence, which could represent a great strategy for the inclusion of the country in the global economic system. The article analyzes the participation of Brazil in some expressive international cultural events, and reflects on culture as an element of soft power in the context of international relations.

\section{KEYWORDS}

Culture, globalization, soft power, cultural diplomacy, olympic games. 


\section{Introdução}

"A memória conta realmente - para os indivíduos, as coletividades, as civilizações - só se mantiver junto a marca do passado e o projeto do futuro, se permitir fazer sem esquecer aquilo que se pretendia fazer, transformar-se sem deixar de ser, ser sem deixar de se transformar."

(ítalo Calvino)

O papel da cultura no desenvolvimento de uma nação parece algo incontestável, mas a fragilidade das políticas públicas na área da cultura evidenciam que, no Brasil, esse debate ainda é incipiente. Ao constatarmos a dificuldade em priorizar a cultura como elemento vital para a formação e o desenvolvimento do brasileiro, vemos que seu papel como eixo de diálogo e de comunicação da imagem de nosso país no exterior talvez seja algo ainda a ser melhor lapidado.

Este artigo, ao identificar momentos emblemáticos em que o Brasil, ao longo de sua trajetória, ousou usar sua cultura como linguagem de expressão, alcançando resultados surpreendentes, propõe uma leitura dos processos de encontros entre diferentes povos e países na dinâmica internacional, em distintos contextos históricos - como disposto nos itens de 2 a 5 . Tais exemplos visam a dialogar com os conceitos expostos e registrar experiências que nossa parca bibliografia sobre o tema ainda está por reunir.

O item 6 (Conclusão) aponta para a necessidade de conscientização de países emergentes, como o Brasil, a respeito do papel que a cultura exerce como elemento primordial para a consolidação de sua imagem no cenário internacional.

\section{A cultura enquanto arma de conhecimento e estratégia de domínio nos con- frontos humanos}

Há milênios os grupos humanos deslocam-se pelo planeta cumprindo a saga de descobrir, conhecer, pesquisar e povoá-lo. Esses deslocamentos fizeram-nos encontrar realidades e situações desconhecidas, que os levaram a desenvolver diferentes capacidades e instrumentos de adaptação a cenários e contextos naturais adversos. Muitos desses artefatos constituem e integram coleções, que contracenam hoje com os capítulos da história universal narrada nos museus enciclopédicos, em todo o mundo.

Ao longo de séculos, esse caminhar pelo planeta possibilitou a escolha ou a necessidade de fixação de grupos humanos em determinados territórios, mas desde sempre permaneceu íntegra a possibilidade de se prosseguir no deslocamento pelo globo terrestre - a busca pelo desconhecido sempre foi um desejo e uma inegável permanência cultural entre os humanos.

Os avanços pelos diferentes continentes, em rotas pioneiras, inesperadas, convergentes ou concomitantes, em direção ao desconhecido, foram constantemente repletos de desafios, de perigos e, muitas vezes, de conquistas. A disputa humana por territórios foi e é motivo de tensão, de negociação, de ocupação e de posse, mesmo nos dias atuais. O contato com outros grupos humanos, em diferentes territórios, foi sempre uma moeda de dupla face. De um lado, o ímpeto de conhecer, de ofertar, de trocar, de se comunicar, de compartilhar conhecimentos. De outro, o medo do desconhecido, o estranhamento diante do outro, a necessidade 
de avançar e dominar, o confronto, a luta, o risco contínuo. Entre o contato e o confronto, os grupos humanos entrecruzaram-se, competiram, lutaram, venceram ou perderam - enfim, comunicaram-se.

Nessa luta incessante pela busca do desconhecido, pelo domínio das técnicas, pela posse do território, pela superação das adversidades naturais, pelo relacionamento e domínio de outras espécies, pela conquista da comunicação humana, os grupos adquiriram e acumularam conhecimentos sobre as suas formas de vida e também com relação aos costumes de outros povos com os quais interagiram em seus longos e desafiantes percursos.

Em um paralelo com o que observa Niall Ferguson, não se pretende aqui compor uma longa narrativa da história da civilização, já que ela "Deve abarcar uma boa porção de tempo e espaço, porque as civilizações não são pequenas e nem efêmeras". Porém, "Àqueles que reclamam do que foi omitido", Ferguson cita o pianista Thelonious Monk: "Não toque tudo (ou o tempo todo); deixe que algumas coisas escapem [...]. O que você não toca pode ser mais importante do que o que você toca." (FERGUSON, 2017, p. 21).

Assim, num voo de pássaro pelo tempo, aterrissamos no século XVI, entre as cartas de Amerigo Vespucci, acompanhadas das primeiras imagens do Novo Mundo, em que narra as aventuras em "espaço aberto e contempla maravilhado 'coisas jamais pensadas'” (BELLUZZO, 1994, p. 18). Constatamos ainda que é atribuído ao cartógrafo alemão Martin Waldssemüller a denominação "América", em 1507:

O nome do lugar nasce do desejo de superar o âmbito lendário, instaurado pela suposição da existência utópica de ilhas e passagens, pela descoberta da terra firme e pelo encontro de um continente habitado. [...] Além do Atlântico tudo era lenda, e, por isso, os testemunhos dos viajantes passam a adquirir foro de verdade e as imagens que suscitam são tidas como evidências (BELLUZZO, 1994, p. 18).

As descobertas e a existência de cada Novo Mundo possibilitaram aos descobridores justapor espaços ocupados por mares e/ou por terras, povoar vazios imaginados, registrar suas hipóteses e percepções, dividi-las e difundi-las por meio de cartas, desenhos, gravuras, registros diversos. Verificou-se ser possível compor mapas transitórios, realísticos ou imaginários, precisos ou não, mas que criavam um sentido de busca de entendimento e de possibilidade de retorno aos locais já navegados ou percorridos. Estava garantida assim a continuidade da conquista e permitida a ocupação transoceânica. Esses esforços foram sequenciais e se transformaram em grandes epopeias que, uma vez disputadas e vencidas, atribuíram poder e riqueza aos seus respectivos reinos financiadores. Pouco a pouco a ciência e as artes foram se moldando à tarefa de conhecer e relatar o Novo Mundo, por meio de histórias fantásticas ilustradas por desenhos e artefatos, espécimes minerais e naturais, que se transformaram num mundo de maravilhas até então jamais conhecidas, que na sequência eram identificadas e expostas nos Gabinetes de Curiosidades europeus. 
Os Gabinetes de Curiosidades abrigavam grandes coleções enciclopédicas de objetos, marcadas por diferentes tipologias, que podiam compreender desde arqueologia, etnografia, geologia, religião, tapeçarias, relíquias diversas, até artes e antiguidades. Também chamados de "Câmaras de Maravilhas", serviam tanto ao deleite de seus detentores como à exposição de raridades vindas dos territórios recém-dominados, como um grande troféu da conquista para os representantes da aristocracia europeia. Esses conjuntos, também conhecidos como "Teatros do Mundo" ou "Teatros da Memória", além de permitirem uma visão onírica do Novo Mundo, atribuíam grande poder aos seus proprietários. Estudos e pesquisas posteriores concluíram que os Gabinetes de Curiosidades representaram, sem dúvida, a gênese dos museus.

Temos, assim, desde o século $\mathrm{XVI}$, o registro das primeiras imagens e informações sobre o nosso território, suas riquezas naturais e o modo de vida de nossos primeiros habitantes, transitando para serem expostos em outros mundos, sujeitos a toda a sorte de leituras e compreensões. Essas coleções de imagens e artefatos, que ainda não haviam sido devidamente estudadas e catalogadas, foram capazes de maravilhar e seduzir o gosto europeu de então. Foram, sem dúvida, os nossos "batedores", nossos primeiros gestos, voluntários ou não, de proposição e interlocução internacionais.

Entre os séculos XVII e XIX, o Brasil foi palco de grandes expedições artísticas e científicas, que o descreveram e forjaram sua imagem durante todo o período colonial. Após a chegada da Corte Portuguesa, em 1808, em consequência das guerras napoleônicas, o Brasil mudou de estatuto, sendo elevado à condição de Reino Unido de Portugal. De colônia totalmente dependente de Lisboa, o Brasil passou a sediar o Reino. Essa mudança conjuntural foi decisiva para o reposicionamento do Brasil no cenário internacional do período. O império nos trópicos, além de incipiente e precário, era também pouco compreendido na Europa e notadamente em Portugal, originando interpretações muitas vezes controversas.

Entre 1851 e 1913, o Brasil participou, embora de forma inconstante, de doze edições de Exposições Universais, grandes mostras que sintetizavam o projeto capitalista internacional. Delas participavam regiões em expansão, como os países europeus e os Estados Unidos; faziam-se representar também alguns países que viviam ainda em regime colonial e eram detentores de fontes de matérias-primas, como os latino-americanos México, Argentina e Brasil. "Uma verdadeira representação do mundo, tal como concebido pela filosofia dominante", como afirma Heloisa Barbuy (1996, p. 211).

A presença do Brasil na Exposição Universal de 1889, em Paris, França, comemorativa do Centenário da Revolução Francesa, foi sem dúvida a de maior relevo, pois contou com o incentivo e apoio pessoal do próprio imperador D. Pedro II, em momento muito próximo à Proclamação da República do Brasil (BARBUY, 1996).

\section{O papel da cultura no diálogo entre as nações}

Nessa trajetória empreendida pelo ser humano desde seus primórdios até a contemporaneidade, passando pelos jogos de sentido de nossos artefatos expostos nos Gabinetes de Curiosidades europeus, em pleno século XVI, e pela presença do 
do Brasil nas grandiosas Exposições Universais, vemos que há uma tríade de longo termo, que se enuncia e se articula.

Como primeiro elemento dessa tríade, registra-se a busca incessante pelo desconhecido, a busca do outro; o segundo, o domínio do território e o desenvolvimento dos artefatos de mediação com o mundo, ou seja, a conquista do conhecimento; e, por fim, a comunicação como estratégia de domínio e sobrevivência. Essa tríade, que foi angular para garantir a sobrevivência da espécie humana, ainda é válida atualmente.

Com o impulso adquirido pelo processo de globalização no século $X X$, a partir da expansão capitalista, tornou-se ainda mais necessário o entendimento das diferentes culturas como estratégia de compreensão dos processos de interação entre os povos. Entender a forma de pensar e agir de uma determinada sociedade passou a ser uma moeda de grande eficácia na percepção do novo, do desconhecido, enfim, do outro. Perceber como se desenvolvem as relações de poder, as formas de articulação, a construção dos pensamentos, a formação histórica, os hábitos culturais, as estratégias de negociação tornou-se algo importante no diálogo e nas disputas entre as nações. Enfim, conhecer um novo país, uma nova aliança de países, um bloco geopolítico, hegemônico ou não, passa por perscrutar as diferentes culturas que ali estavam agrupadas, contrapostas, articuladas ou que até mesmo se manifestassem em movimentos antagônicos.

A cultura tem, portanto, o papel de elo de sentidos, de transposição, de entendimento e de diálogo entre nações. Ela é capaz de atrair, engajar, encantar diferentes atores sociais, além de enunciar novas formas de expressão e de conquista.

Como vimos, a partir do século passado, o mundo vem ensaiando o uso da cultura como linguagem de expressão e articulação nas relações internacionais, entre diferentes povos.

$\mathrm{O}$ artefato símbolo do contato entre o europeu e o indígena exposto num museu europeu, a coroa do Divino das faustas festas do barroco brasileiro elevada a obra referencial da exposição Brasil Barroco - entre o céu e a terra, realizada no Petit Palais, em Paris (2000); os painéis Guerra e Paz, de Candido Portinari, entronizados na sede das Nações Unidas (ONU), em Nova York (2015), depois de restaurados e expostos, no Brasil e na França; uma obra de Ligia Clark exposta no MoMA em Nova York; ou o rufar dos tambores de uma apresentação brasileira no México ou no Afeganistão, são símbolos de poder de nossa cultura, são atributos de memória, são enunciados estéticos, são ritos históricos ou contemporâneos de afirmação cultural e socioeconômica. Dão conta de nossas múltiplas narrativas históricas, simbólicas e humanas. Falam de um país emergente, com um percurso histórico complexo, com um contingente populacional rico e diverso, que convive com injustiças e desigualdades sociais e com a insegurança pessoal e coletiva, em tempo real. Contam sobre nossas instabilidades, mas também sobre nossa capacidade de superação. Evidenciam, enfim, os valores intrínsecos da cultura brasileira.

\section{A cultura brasileira como elemento de soft power e o desafio de construir a imagem do Brasil no exterior}

Um novo conceito, que vem sido amplamente utilizado para a análise de 
relações internacionais, foi elaborado em 2004 por Joseph Nye, cientista político da Harvard University. Nye adota a expressão soft power para definir a "capacidade de um país de influenciar e persuadir por meio de seu poder de inspiração e atração, em contraposição ao poder militar ou de coerção (hard power). Segundo Nye, o soft power emanado por um país se deve sobretudo à admiração que sua cultura, seus valores, sua língua, suas instituições e suas ações no âmbito internacional são capazes de despertar. [...] Já o Brasil, por exemplo, tem um soft power natural graças ao apelo de sua cultura (e do futebol) [...]." (COELHO, 2010).

O Brasil contemporâneo pode inscrever nessa narrativa, ao longo das duas primeiras décadas do século XXI, alguns exemplos que se tornaram emblemáticos e que evidenciaram como o nosso soft power, por meio da cultura, pode ser poderoso, potencialmente capaz de nos elevar a novas posições no cenário internacional.

Foi o caso do Ano do Brasil na França, realizado pelo governo brasileiro, em 2005. Um conjunto de mais de 400 ações culturais orquestradas, e com um plano de comunicação muito bem estruturado, foi capaz de encantar a França e o público de mais de 15 milhões de pessoas que participaram do evento, reposicionando assim a marca Brasil no cenário franco-europeu. Esse grande evento cultural teve a participação de mais de 2 mil artistas, palestrantes, produtores e técnicos brasileiros, que juntos realizaram mais de 200 exposições, 850 espetáculos e apresentações, cerca de 80 colóquios e eventos literários, além de 1.300 exibições de audiovisual. Os resultados de mídia foram também surpreendentes, pois foram gerados 15 mil artigos na mídia impressa, 35 edições especiais, totalizando a venda de 8 milhões de exemplares. Somam-se a esse impacto comunicacional 82 programas de TV e 66 de rádio, que garantiram uma mídia incomum para eventos dessa natureza. Enfim, os investimentos compartilhados entre o governo brasileiro e o francês, que garantiram esse conjunto de ações culturais brasileiras na França, abrangendo diferentes linguagens artísticas, apresentadas em Paris e em mais de 160 cidades francesas, certamente foram pequenos em relação aos resultados positivos que a melhoria da imagem do país pôde incutir nas trocas comerciais e em estratégias político-institucionais bilaterais (2005 - ANO DO BRASIL NA FRANÇA, 2005, p. 16-17). 


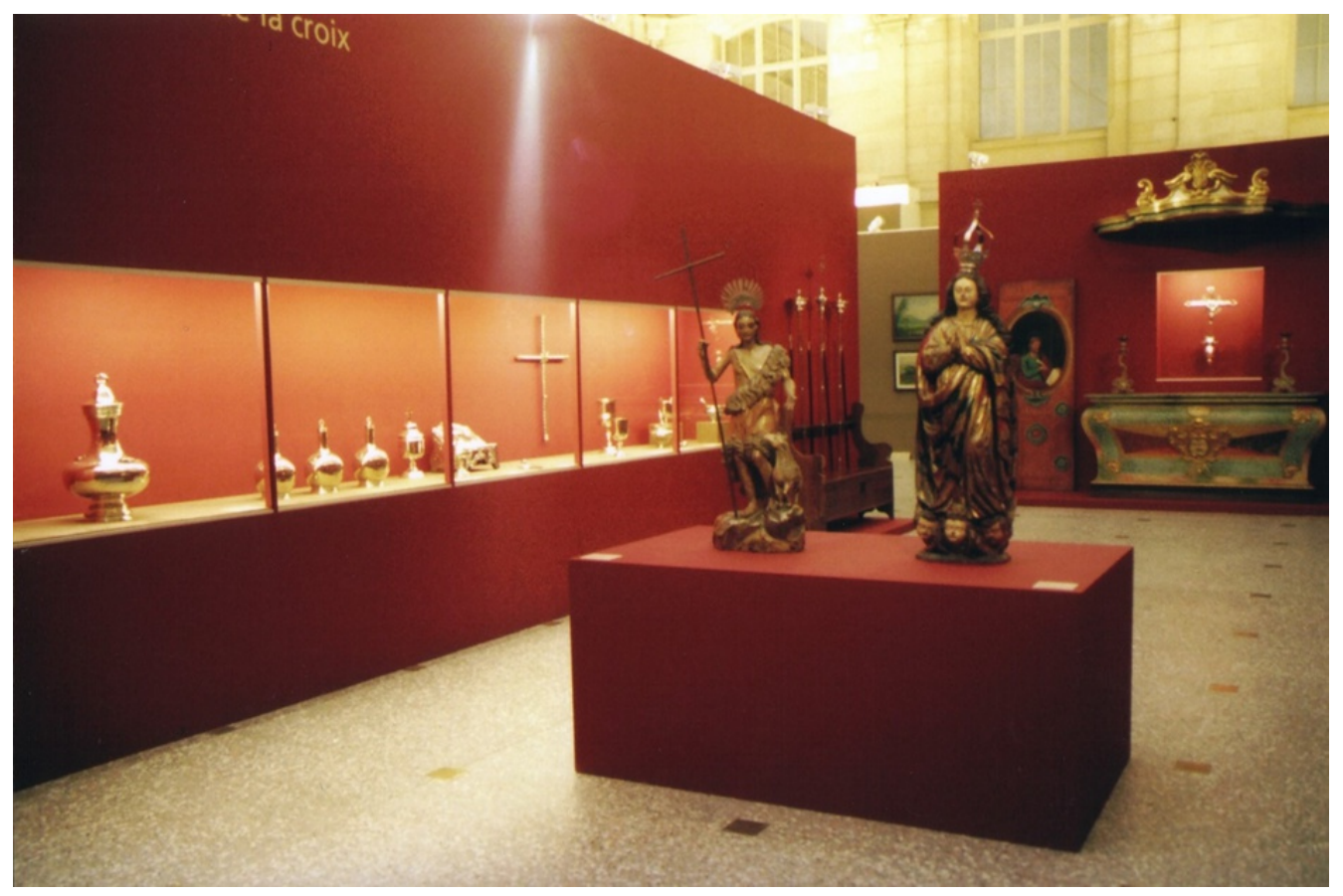

Figura 1. Exposição Três Séculos de Arte Brasileira: Coleção Beatriz e Mário Pimenta Camargo, realizada no Musée des Beaux-Arts de Rouen, na França, evento incluído nas Comemorações do Ano do Brasil na França, em 2005. Fotografia do Arquivo Expomus.

Outro exemplo atual e muito impactante foi o espetáculo de abertura dos Jogos Olímpicos realizados no Rio de Janeiro. O misto de arte, tecnologia, inovação e sustentabilidade surpreendeu e encantou 342 milhões de pessoas, em todo o mundo. A cultura brasileira foi o centro das atenções mundiais por quase duas horas, com um roteiro sintético e estratégico, que evidenciou de forma encantadora e competente o seu poder transformador. Essa apresentação deu o tom correto e bem-humorado aos Jogos Olímpicos de 2016 e mostrou nossa face competente e ambientalmente responsável. Numa só apresentação, foram desmistificados vários preconceitos e diversas visões equivocadas sobre o Brasil. Evidenciou-se o valor maior da cultura brasileira, dando destaque a projetos e conjuntos patrimoniais de relevância. Num aceno claro à necessidade de proteção ao planeta, a apresentação primou por uma chancela ambientalmente correta, não apenas nos conteúdos apresentados, que foram abrangentes, mas também na seleção e uso dos materiais. Com recursos contidos, os criadores desse espetáculo mostraram que a genialidade e a capacidade de planejamento e superação do brasileiro podem atingir resultados surpreendentes e realizar projetos de grande complexidade, alcançando impacto global positivo. ${ }^{1}$

\footnotetext{
1 Mais sobre a repercussão mundial da cerimônia de abertura dos Jogos Olímpicos no Brasil está disponível em <http://esportes.estadao.com.br/noticias/jogos-olimpicos,confira-a-repercussao-internacional-da-cerimoniade-abertura-do-rio-2016,10000067393> Acesso: 20 jul. 2017.
} 


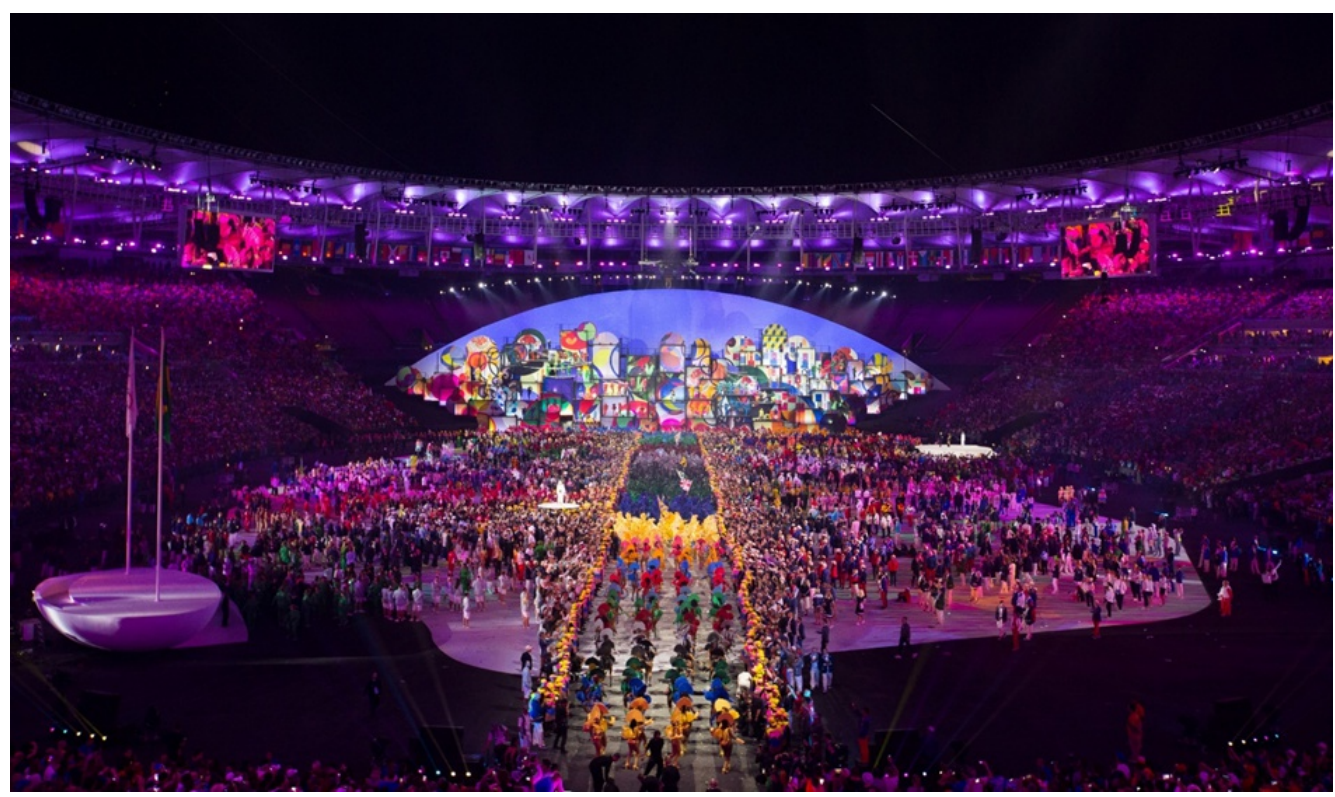

Figura 2. Abertura dos Jogos Olímpicos 2016 no Rio de Janeiro. Fotografia de Gabriel Nascimento.

No entanto, o ranking global de soft power - publicado anualmente pelo Center on Public Diplomacy (CPD) da University of Southern California (USC), em parceria com a Portland, empresa de consultoria em comunicação estratégica aponta em sua terceira edição, lançada em julho de 2017, que o Brasil caiu de 24은 para 29ㅇ lugar entre os 30 países do ranking (MCCLORY, 2017, p.43). Os pesquisadores da Portland/USC concluíram que o Brasil parece não ter acertado em mascarar, com os Jogos Olímpicos, o clima de grave crise econômica, política e social que o país atravessa (MCCLORY, 2017, p. 50).

\section{A sociedade brasileira e seu papel estratégico nas políticas internacionais do país}

Considera-se, sob um espectro mais amplo ao analisar a política externa brasileira na segunda metade do século XX e nas duas primeiras décadas do século XXI, que possa ter havido um estreitamento dessa atuação, ou seja, um certo cerceamento das relações internacionais. Essa hipótese, de alguma forma, contraria o senso comum de que o Brasil é um país aberto, disposto ao diálogo e muito vocacionado ao "encontro com o outro". Esse conceito seria válido no âmbito das relações pessoais, mas talvez não fosse institucionalizado como política externa brasileira.

O que se observa com frequência é um país preocupado em assegurar formas internas e externas de protecionismo a bens e serviços, em garantir múltiplas formas de proteção e incentivos governamentais, e relativamente pouco encorajado a enfrentar as duras regras de comércio internacional. 
Por outro lado, é preciso considerar que a política externa brasileira talvez não devesse ser planejada e articulada apenas por meio das ações governamentais e, de forma específica, pelo Ministério das Relações Exteriores e pela APEX-Brasil. ${ }^{2}$

Trata-se, na verdade, de um desafio para toda a sociedade brasileira, envolvendo todas as instâncias articuladoras da economia, ou seja, indústria e comércio, agroindústria, inovação, tecnologia, meio ambiente, turismo, esportes e cultura, entre outras.

\begin{abstract}
O problema fundamental que as pessoas não gostam de falar muito é que política externa e relações internacionais têm baixa prioridade na agenda da sociedade brasileira. O Brasil ainda é um país muito voltado para si mesmo. Durante muitos anos, as pessoas pensaram que política externa é uma coisa voltada para diplomatas, o que não é verdade. Na verdade, os diplomatas são assessores em termos de política externa e são responsáveis pela sua execução. Mas a política é dada pela sociedade brasileira, pelo Governo e pelos políticos, digamos assim (CASTRO NEVES, 2017).
\end{abstract}

Observamos, portanto, que nossa política internacional talvez não prime pela consistência e pelo arrojo em empreender ações de longo prazo e de forma sistêmica, alavancando diferentes setores econômicos da sociedade brasileira, passíveis de serem internacionalizados.

Podemos analisar alguns exemplos de países que se reinventaram em termos de política externa nos últimos 40 anos. Talvez o caso mais curioso seja o da China, que alcançou um novo patamar de articulação internacional, como bem observa o embaixador Luiz Augusto Castro Neves3:

A grande estratégia hoje da diplomacia nacional seria a inserção do Brasil na economia mundial, aquilo que os chineses chamam de inserção no sistema internacional, que fez parte das reformas de 1978 feitas por Den Xiaoping. O grande objetivo da China foi se inserir no sistema internacional, e, de país isolado e fechado que era, mudou sua percepção e se colocou muito bem neste sistema internacional. $\mathrm{O}$ Brasil continua até hoje, em grande medida, como um país voltado para dentro. O próprio setor industrial, que foi essencialmente construído com base na substituição de importações, subsídios, reserva de mercado e protecionismo (CASTRO NEVES, 2017).

Na fala acima do embaixador, há um detalhe importante a observar. Ele diz que a grande estratégia da diplomacia nacional seria a inserção do Brasil na economia mundial, "aquilo que os chineses chamam de inserção no sistema internacional". Os chineses reconhecem e atuam globalmente considerando não só a economia mundial como alvo das suas relações globais, mas bem mais do que

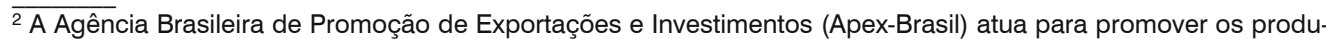
tos e serviços brasileiros no exterior e atrair investimentos estrangeiros para setores estratégicos da economia brasileira. Diponível em <http://www.apexbrasil.com.br/home/index> Acesso: 20 jul. 2017.

3 O embaixador Luiz Augusto Castro Neves é presidente do Conselho Empresarial Brasil-China e vice-presidente emérito do Cebri - Centro Brasileiro de Relações Internacionais.
} 
isso: consideram como estratégia maior o país se inserir no sistema internacional. Isso permite considerar que esse sistema engloba muito mais do que os fatores macroeconômicos, ou seja, as trocas entre países, blocos ou parceiros econômicos. O conceito de sistema internacional parece sugerir o reconhecimento das configurações político-econômicas complexas e por vezes dissonantes, o respeito à legislação e os avanços em termos de novas perspectivas do direito internacional; consciência relativa às complexas corresponsabilidades sociais, patrimoniais e ambientais; estratégias e prevenção colaborativa em termos de segurança internacional, e outros tantos fatores de alinhamento e/ou distanciamento entre as nações.

Vemos que a ação internacional da China segue um planejamento político maior, bastante claro, que articula e coordena as demais ações de sua política externa, em distintos continentes. Destaca-se, nesse sentido, como um dos exemplos mais expressivos dessa estratégia - conforme relatou Lanxin Xiang ${ }^{4}$ em debate realizado na Fundação FHC, em 2016 -, a iniciativa desenvolvida pelo governo chinês e

apelidada de "One Belt \&One Road" (OBOR), que, em português, seria algo como "um cinturão \& uma estrada". A ideia é conectar o território chinês, por meio de estradas, ferrovias, oleodutos e gasodutos, à Rússia e aos países da Ásia Central e do Oriente Médio, chegando até a Europa (do Leste e do Sul). Além da integração externa, o projeto busca incorporar à dinâmica do desenvolvimento chinês, muito concentrado na região da costa do Pacífico, as regiões situadas no centro e no oeste do país, bem mais pobres e atrasadas (XIANG, 2016).

Essas diretrizes abrangem igualmente o plano interno do país, ou seja, há uma articulação entre os fluxos internos e externos, com ganhos de eficiência, flexibilidade e agilidade das decisões e ações governamentais e empresariais.

Outro exemplo digno de nota é o fato de que a China se reposicionou nos últimos vinte anos - assumiu relevância nos conselhos e financia parte dos orçamentos das organizações patrimoniais globais; sediou os principais eventos internacionais nas áreas de esportes e cultura; a despeito de seus graves problemas de controle ambiental, assume um papel de destaque nas discussões de políticas globais de proteção ao meio ambiente e procura adotar hoje soluções ambientalmente corretas em suas novas plantas industriais; além de investir fortemente em formação de suas lideranças e fortalecer as suas representações formais no exterior. $O$ país tem assinado protocolos de colaboração com as principais universidades de relevo internacional para o desenvolvimento sistemático de pesquisas nas múltiplas áreas de mútuo interesse, destacando-se a formação bilateral e o desenvolvimento de programas internacionais de educação e cultura, inclusive com concessão de bolsas para estudantes estrangeiros.

É importante esclarecer que, apesar de a China se destacar hoje no cenário internacional, aqui não se coloca propriamente um juízo de valor e nem de aderência à sua política econômica, já que o que está em análise é o planejamento, a articulação, sua forma de inserção no sistema global e a vontade política que foi empreendida para organizar esse salto, ou seja, a mudança de patamar e de engajamento por meio de ações de amplo espectro, em termos de política internacional.

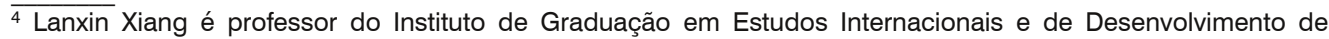
Genebra (Suíça), pesquisador, autor, e dirige o Centro de Estudos 'One Belt \& One Road'.
} 
Cabe ao Brasil desenvolver um planejamento sistêmico e harmônico entre as esferas governamentais que se responsabilizam pelas relações internacionais, arregimentando as demandas institucionais, econômicas, comerciais, ambientais e culturais, a fim de construir um discurso coeso e consistente, em conjunto com a sociedade brasileira, que possa sustentar a imagem do país em sua dinâmica internacional.

\section{Conclusão}

Muitos dos países desenvolvidos já se conscientizaram sobre o papel da cultura como elemento essencial para a consolidação de sua imagem no cenário internacional, e os países chamados "emergentes" têm-se esforçado para assimilar novas práticas de utilização de seus atributos patrimoniais e artísticos como selo de excelência e elo para novas conquistas econômicas e sociais. O valor da cultura é tema ainda frágil no Brasil e relativamente pouco discutido em âmbito nacional. Embora tenhamos um legado cultural altamente expressivo e de grande impacto na geração de empregos e renda nas distintas regiões brasileiras, a cultura não é ainda compreendida internamente no país como um valor real, como um ativo capaz de promover o bem-estar social. Talvez tenhamos mesmo que avançar nas discussões sobre economia da cultura no Brasil e, uma vez fortalecidos neste sentido, ousar novos empreendimentos em termos de política externa.

Já não seria sem tempo que, em pleno século XXI, pudéssemos acreditar no papel que a cultura representou historicamente nas relações de proteção ou domínio entre as distintas civilizações no mundo. Ela jamais foi moeda acessória nos momentos de aproximação, conquista ou dominação, nos mais distintos caminhos de enfrentamento entre as nações. Analisar a trajetória da cultura como elemento de fortalecimento das relações geopolíticas e econômicas certamente evidenciará um cenário futuro mais estimulante e abrangente a ser conquistado.

À cultura brasileira cabe transcender o real e se emular em diferentes papéis de representação nacional, mostrando suas possibilidades de colaborar para suscitar respeito, transparência e admiração de outras nações pelo Brasil. As perspectivas de desenvolvimento futuro de tais ações pelos órgãos responsáveis pela política externa brasileira são ainda incipientes, mas podem vir a ser encorajadas dentro de programas vindouros. Mais do que observar a performance de outros países que atuam de forma arrojada e consistente no cenário internacional, devemos nos conscientizar de nosso valor cultural e utilizá-lo com elemento fundador de nossas ações internacionais.

\section{Referências}

2005 - ANO DO BRASIL NA FRANÇA [Relatório final]. Brasília: Gráfica Brasil, dez. de 2005, p. 16-17.

BARBUY, Heloisa. "O Brasil vai a Paris em 1889: um lugar na Exposição Universal”. In: Anais do Museu

Paulista. São Paulo. N. Sér. v.4 p.211-261 jan./dez. 1996. Disponível em <http://www.revistas.usp.br/anaismp/article/view/5342/6872> Acesso: 20 jul. 2017. 
BELLUZZO, Ana Maria de M. O Brasil dos Viajantes. São Paulo, Edição Metalivros/Fundação Odebrecht, 1994, 3 vol. Vol. 1, Imaginário do Novo Mundo, p. 18.

CALVINO, Italo. "As Odisseias na Odisseia", in: MOULIN, Nilson (trad.), Por que Ler os Clássicos. São Paulo: Companhia das Letras, 1993. Apud BELLUZZO, Ana Maria de M. O Brasil dos Viajantes. São Paulo, Edição Metalivros/Fundação Odebrecht, 1994, 3 vol. Vol. 1, Imaginário do Novo Mundo, p. 13.

CASTRO NEVES, Luiz Augusto. "Exclusivo - Embaixador Castro Neves: 'Política externa não é prioridade para o Brasil'”. Entrevista concedida a Sputnik Brasil. 02 jun. 2017. Disponível em: $<$ https://br.sputniknews.com/opiniao/201706028555529-exclusivo-embaixador-castro-neves-politicaexterna-brasil/>. Acesso: 20 jul. 2017.

COELHO, Luciana. "Cientista político de Harvard criou conceito de 'soft power'”. FOLHA.com. 2 nov. 2010. Disponível em <https://noticias.bol.uol.com.br/brasil/2010/11/02/cientista-politico-de-harvard-criouconceito-de-soft-power.jhtm> Acesso: 20 jul. 2017.

FERGUSON, Niall. Civilização Ocidente X Oriente. São Paulo: Editora Planeta do Brasil, 2017, p. 21.

MCCLORY, Jonathan. The Soft Power 30 - A Global Ranking of Soft Power 2017. Portland/The USC Center on Public Diplomacy, 2017, p. 43;50. Disponível em <http://softpower30.com/wpcontent/uploads/2017/07/The-Soft-Power-30-Report-2017-Web-1.pdf> Acesso: 30 jul. 2017.

XIANG, Lanxin. A China sob Xi Jinping: o que quer e o que pode o líder chinês? [Debate] São Paulo: Fundação FHC, 18 out. 2016. Disponível em <http://fundacaofhc.org.br/debates/a-china-sob-xi-jinping-oque-quer-e-o-que-pode-o-lider-chines> Acesso: 20 jul. 2017.

Receido em 15/06/2017 - Aprovado em 21/08/2017 